\title{
Energy thermal management in commercial bread-baking using a multi-objective optimisation framework
}

\section{Zinedine Khatir $^{a^{*}}$, A.R. Taherkhani ${ }^{b}$, Joe Paton ${ }^{\text {b }}$ Harvey Thompson $^{\text {b }}$, Nik Kapur ${ }^{b}$ and Vassili Toropov ${ }^{\mathbf{c}}$}

\author{
a Institute for Computational and Systems Science, University of Leeds, LS2 9JT, United Kingdom \\ ${ }^{\mathrm{b}}$ School of Mechanical Engineering, University of Leeds, LS2 9JT, United Kingdom \\ ${ }^{\mathrm{c}}$ School of Engineering and Materials Science, Queen Mary, University of London, E1 4NS, United Kingdom \\ * Corresponding author. Email: zkhatir@hotmail.com; \\ Tel. +447877511200
}

\begin{abstract}
In response to increasing energy costs and legislative requirements energy efficient high-speed air impingement jet baking systems are now being developed. In this paper, a multi-objective optimisation framework for oven designs is presented which uses experimentally verified heat transfer correlations and high fidelity Computational Fluid Dynamics (CFD) analyses to identify optimal combinations of design features which maximise desirable characteristics such as temperature uniformity in the oven and overall energy efficiency of baking. A surrogate-assisted multi-objective optimisation framework is proposed and used to explore a range of practical oven designs, providing information on overall temperature uniformity within the oven together with ensuing energy usage and potential savings.
\end{abstract}

Keywords Energy efficiency, Commercial bread-baking oven, Multi-objective design optimisation, Computational fluid dynamics, Experimentation, Pareto front.

\section{Nomenclature}

$\begin{array}{ll}\text { Abbreviation } & \\ \text { CFD } & \text { Computational fluid dynamics } \\ \text { DOE } & \text { Design of experiments } \\ \text { BC } & \text { Boundary condition }\end{array}$

Symbols

$\begin{array}{ll}\mathrm{c}_{\mathrm{p}} & \text { Specific heat capacity }[\mathrm{J} /(\mathrm{kg} \mathrm{K})] \\ \mathrm{d} & \text { Nozzle jet diameter }[\mathrm{m}] \\ \mathrm{f} & \text { Relative orifice area } \\ \mathrm{H} & \text { Nozzle-to-surface distance }[\mathrm{m}] \\ \mathrm{H} / \mathrm{d} & \text { Dimensionless nozzle-to-surface distance } \\ \mathrm{h}_{\mathrm{c}} & \text { Heat transfer coefficient }\left[\mathrm{W} /\left(\mathrm{m}^{2} \mathrm{~K}\right)\right] \\ \mathrm{I} & \text { Turbulence intensity } \\ \mathrm{L} & \text { Characteristic length }[\mathrm{m}] \\ \mathrm{k} & \text { Thermal conductivity }[\mathrm{W} /(\mathrm{mK})] \\ \mathrm{Nu} & \text { Nusselt number }\left[\mathrm{Nu}=\mathrm{h}_{\mathrm{c}} \mathrm{d} / \mathrm{k}\right] \\ \mathrm{P} & \text { Power }[\mathrm{kW}] \\ \mathrm{p} & \text { Pressure }[\mathrm{Pa}] \\ \mathrm{Q} & \text { Volumetric flow rate }\left[\mathrm{m}^{3} / \mathrm{s}\right] \\ \mathrm{Pr} & \text { Prandtl number }[\mathrm{Pr}=\mathrm{v} / \tau] \\ \mathrm{q} & \text { Heat flux }\left[\mathrm{W} / \mathrm{m}^{2}\right] \\ \mathrm{Re} & \text { Reynolds number }\left[\mathrm{Re}=\mathrm{u}_{\text {noz }} \mathrm{d} / \mathrm{v}\right] \\ \mathrm{s} & \text { Nozzle-to-nozzle spacing }[\mathrm{m}] \\ \mathrm{t} & \text { Time }[\mathrm{s}]\end{array}$




$\begin{array}{ll}\mathrm{T} & \text { Temperature }[\mathrm{K}] \\ \mathrm{u}_{\text {noz }} & \text { Nozzle velocity }[\mathrm{m} / \mathrm{s}] \\ \mathrm{V}_{\text {in }} & \text { Velocity inlet condition }[\mathrm{m} / \mathrm{s}] \\ \mathrm{w} & \text { Nozzle to nozzle width spacing [m] } \\ \mathrm{x} & \text { Distance from centre of nozzle }[\mathrm{m}] \\ \mathrm{x}_{1,2,3} & \text { Design variables } 1,2 \text { and } 3 \\ \alpha & \text { Degree of gelatinisation } \\ \varepsilon & \text { Emissivity } \\ \rho & \text { Density }\left[\mathrm{kg} / \mathrm{m}^{3}\right] \\ v & \text { Kinematic viscosity }\left[\mathrm{m}^{2} / \mathrm{s}\right] \\ \sigma & \text { Stefan-Boltzmann constant }\left[\sigma=5.67 \times 10^{-8} \mathrm{Wm}^{-2} \mathrm{~K}^{-4}\right] \\ \sigma_{\mathrm{T}} & \text { Temperature functional for minimization, }[\mathrm{K}] \\ \sigma_{\text {cooking }} & \text { Cooking time functional for minimization, }[\mathrm{min}] \\ \sigma_{\mathrm{i}} & \text { Standard deviation of minimum distance of } \mathrm{DOE} \\ \theta & \text { Closeness-of-fit parameter } \\ \tau & \text { Thermal diffusivity }\left[\mathrm{m}^{2} / \mathrm{s}\right]\left[\tau=\mathrm{k} /\left(\rho \mathrm{pc}_{\mathrm{p}}\right)\right]\end{array}$

$\begin{array}{ll}\text { Subscript } & \\ \mathrm{b} & \text { Model building DOE } \\ \mathrm{i} & \text { Index i } \\ \mathrm{j} & \text { Index j } \\ \mathrm{m} & \text { Combined model DOE } \\ \mathrm{v} & \text { Model validation DOE }\end{array}$

\section{$1 \quad$ Introduction}

The worldwide commercial bread baking sector is a hugely significant manufacturing industry, with over 94 million tonnes of bread consumed each year [1]. The baking process is of major environmental importance as it is the most energy intensive process in the bread manufacturing cycle, consuming an estimated $804 \mathrm{~kJ}$ per $\mathrm{kg}$ of bread [2], and ultimately determines many of the final physical properties of bread, such as crust colour, crumb texture and taste [3].

Traditionally, energy efficiency has not been the main goal in oven design with other features such as ease and reliability of operation, access for cleaning, costs of maintenance, consistency of production and ability to cope with high production rates being of greater importance. This has resulted in typical commercial bread ovens having efficiencies of less than $50 \%[2,4]$. Higher energy prices and the increasing importance of environmental sustainability and corporate responsibility have led to much greater incentives to reduce energy consumption within industrial ovens [5] as required by the European Energy Efficiency Directive [6]. This Directive, which entered into force on 4 December 2012, establishes a common framework of measures for the promotion of energy efficiency within the European Union (EU) in order to ensure the achievement of the EU's $202020 \%$ target on energy efficiency. Recent research has identified significant opportunities for energy savings and the need to develop procedures for thermal optimisation within manufacturing processes as discussed in Ref. [7]. A systematic approach has been constructed embedding key process variables to engineer optimized industrial ovens $[7,8]$. Accordingly the present paper proposes a scientifically-rigorous methodology for optimising the energy consumption within commercial baking ovens.

Baking ovens can be classified broadly according to the heating method used: either direct-fired or indirect-fired ovens. In the direct-fired approach the combustion products come into contact with the bread, whilst the latter use heat exchangers to separate the products of combustion from the baked product. Commercial bread ovens can typically be in the region of 30 to $40 \mathrm{~m}$ long, baking up to 10 tonnes of bread per hour on a continuous basis. The focus of the present study is on forced convection ovens, which transfer heat to the surface of the dough from hot air issuing out of jet impingement nozzles, drying and setting the bread crumb structure, see Fig. 1. The rate of convective heat transfer to the surface of the bread, which is often specified in terms of a convective heat transfer coefficient, 
is a function of the air jet velocity and temperature, and important geometric variables -specifically those associated with the nozzles orifices: the nozzle-to-surface distance, hole diameter and spacing.

Figure 1: Schematic diagram of a forced convection commercial bread oven:

(a) Overall view and (b) Cross section view.

Several experimental studies on jet impingement heat transfer have appeared in the literature, prominent among these being the work of Martin [9], who published heat transfer correlations for a number of different types of nozzles and arrays of nozzles. These have, however, focussed on lower impingement velocity cases than is relevant for many modern baking ovens. The present study uses experimental heat transfer coefficient correlations taken for the specific oven operating conditions of interest here.

Computational Fluid Dynamics (CFD) is now used widely to predict airflows in the food industry [10] and is increasingly being used an alternative to experimental design of baking ovens. Previous relevant CFD studies of bread ovens have predicted air flow and temperature distribution within baking ovens [11] and to optimise temperature uniformity at the bread surface for a baking regime in order to improve energy efficiency [12]. CFD has also been used to reduce moisture loss [13, 14] by altering the temperature profile along the length of the oven; to optimise temperature, heat transfer coefficient and bread radius (i.e. dough shape) to improve product quality [15]; and to optimise product quality for various combinations of heating sources [16].

This paper provides the first multi-objective optimisation framework to design energy efficient commercial bread-baking ovens with high fidelity CFD analysis using experimental measurements of heat transfer coefficient. The conceptual model will then be used to generate a Pareto front which provides a formal mechanism for balancing the multi-objective optimisation criteria of minimising temperature uniformity and cooking time, enabling the specific energy consumption to be minimised for commercial high-speed air impingement ovens.

\section{$2 \quad$ Materials and methods}

\subsection{Heat transfer coefficient correlation}

An optimisation methodology is developed, which can be used to reduce the specific energy consumption of bread baking. A key aspect of this is determining the heat transfer coefficient, $\mathrm{h}_{\mathrm{c}}$, which enables the heat transfer into the bread from the hot gas to be determined. A recent experimental study of the heat transfer in high-speed air impingement baking ovens provides convective heat transfer coefficients relevant to the baking industry $[13,14]$. These were found to be generally consistent with Martin's [9] correlations, with a difference of less than $12 \%$ over the operating range considered. Martin's [9] heat transfer correlation is written in dimensionless form in terms of the Nusselt and Reynolds numbers and is given by Eq. (1):

$$
\frac{\mathrm{Nu}}{\operatorname{Pr}^{0.42}}=K(\mathrm{H} / \mathrm{d}, \mathrm{f}) \cdot \sqrt{\mathrm{f}} \frac{1-2.2 \sqrt{\mathrm{f}}}{1+0.2(\mathrm{H} / \mathrm{d}-6) \sqrt{\mathrm{f}}} \mathrm{Re}^{2 / 3}
$$

where $K(H / d, f)=\left\{1+[(H / d) /(0.6 / \sqrt{ } f)]^{6}\right\}^{-0.05}$, f represents the free area of the bank of nozzles, $d$ the nozzle jets diameter and $\mathrm{H} / \mathrm{d}$ a dimensionless ratio (i.e. where $\mathrm{H}$ is the distance between the nozzle and the top surface of the product) as indicated in Fig. 2. The optimisation strategy described below uses three design variables: two geometric variables $\mathrm{x}_{1}=\mathrm{d}$ and $\mathrm{x}_{2}=\mathrm{H} / \mathrm{d}$ and one operating variable, the air speed at nozzle inlets $\mathrm{x}_{3}=\mathrm{u}_{\text {noz }}$. The combination of the air speed and temperature enables the electrical energy (fans) and heat energy (gas) consumption to be estimated. 
Equation (1) enables the convective heat transfer coefficient $h_{c}$ to be written as the following explicit function of these design variables:

$$
h_{c}=\frac{\operatorname{kPr}^{0.42} K(H / d, f) \cdot \sqrt{f}}{d} \cdot \frac{1-2 \cdot 2 \sqrt{f}}{1+0.2(H / d-6) \sqrt{f}}\left(\frac{\mathrm{u}_{\mathrm{noz}} \mathrm{d}}{v}\right)^{2 / 3}
$$

An overview of the proposed optimisation methodology is given in Figure 3. The parameter $\mathrm{K}(\mathrm{H} / \mathrm{d}, \mathrm{f})$ in equation (2) is determined experimentally and enables $h_{c}$ to be predicted as a function of the three design variables. This provides the thermal boundary condition for a high fidelity CFD analysis of the thermal airflow which predicts temperature uniformity in the baking chamber, commonly used within the industry as an indicator of product quality. The heat transfer coefficient is also used to predict conductive heat transfer through the bread, which determines the overall baking time. The goal of the optimisation process is to search throughout the design space of $\mathrm{d}, \mathrm{H} / \mathrm{d}$ and $\mathrm{u}_{\mathrm{noz}}$ values to achieve the most appropriate compromise between a good temperature uniformity and a minimal baking time. The CFD and bake time modelling and optimisation strategy are described below.

Figure 2: Representative geometry of a nozzle configuration showing design variables: nozzle jet diameter, $d$, jet velocity, $\mathrm{u}_{\mathrm{noz}}$ and distance $\mathrm{H}$ between the nozzle jet and the bottom wall, with nozzle to nozzle distance spacing, $\mathrm{s}=0.2 \mathrm{~m}$ and $\mathrm{w}=0.04 \mathrm{~m}$.

Figure 3: Process diagram emphasising the link between energy savings and high fidelity design optimisation.

\subsection{Computational fluid dynamics}

Thermal air flows in bread baking ovens are highly complex recirculating flows. Previous studies have shown that reasonable agreement with experimental measurements can be achieved by solving the steady-state Navier- Stokes equations for 3D flow using the SIMPLE algorithm [17]. Turbulence is modelled using the realizable $\mathrm{k}-\varepsilon$ transport model [18-20]. The continuity, momentum and turbulence transport equations are solved numerically using ANSYS FLUENT 14.0 [21].

Figure 4: Top view of the perforated plate and the solution zone (dotted line) used for computational simulations.

The efficiency of the CFD calculations is improved by exploiting symmetry, which enables the flow to be solved only within the solution domain shown in Fig. 4, using the generic model defined in Fig. 5 .

Figure 5: Generic model of the oven baking chamber showing the boundary conditions.

The flow domain shown in Fig. 5 is composed of a combination of flow inlets and outlets, symmetry planes and walls. For flow inlets the temperature, velocity and turbulence conditions are specified and at outlets the pressure, temperature and turbulence conditions are specified. Along the walls the temperature and heat transfer coefficients are specified (see Table 1). Following Wang and Mujumdar [22], turbulence intensity and length scale at the nozzle jets and outlets are set to be $0.5 \%$ and $0.07 \mathrm{D}$ respectively. 
Table 1

Summary of the boundary conditions.

\begin{tabular}{|c|c|c|c|}
\hline $\begin{array}{l}\text { Modelled } \\
\text { Equation }\end{array}$ & Inlet & Outlet & Wall \\
\hline Energy & $\mathrm{T}=513 \mathrm{~K}$ & $\mathrm{~T}=513 \mathrm{~K}$ & $\begin{array}{ll}\text { Top) } & T=513 \mathrm{~K} \\
\text { (Bottom) } & \text { Convective BC } \\
\text { where } \mathrm{h}_{\mathrm{c}}=\mathrm{f}\left(\mathrm{d}, \mathrm{H} / \mathrm{d}, \mathrm{u}_{\mathrm{noz}}\right)\end{array}$ \\
\hline Momentum & $\mathrm{V}_{\mathrm{in}}=\mathrm{u}_{\mathrm{noz}}$ & $\begin{array}{l}\text { Gauge pressure } \\
\mathrm{P}=0 \mathrm{~Pa}\end{array}$ & No-slip \\
\hline $\begin{array}{l}\text { Turbulence: } \\
\text { Length scale } \\
\text { Intensity }\end{array}$ & $\begin{array}{l}1_{\text {scale }}=0.07 \mathrm{D} \\
\mathrm{I}=0.5 \%\end{array}$ & $\begin{array}{l}1_{\text {scale }}=0.07 D \\
\mathrm{I}=0.5 \%\end{array}$ & Wall function \\
\hline
\end{tabular}

The flow domain is meshed using ANSYS workbench and design modeller and the effect of grid density on the flow predictions is examined by varying the number of grid cells and their distribution. Fine mesh resolution is used near the bottom wall to ensure that $\mathrm{y}+$ is below unity for all cases to suitably resolve the near wall region. Grid independence is achieved with around 1.2 million cells.

The CFD solutions are used to predict the temperature uniformity functional, $\sigma_{\mathrm{T}}$, defined by Eq. (3):

$$
\sigma_{\mathrm{T}}=\sqrt{\frac{\int\left(\mathrm{T}-\mathrm{T}_{\text {zone }}\right)^{2} \mathrm{dV}}{\int \mathrm{dV}}}
$$

where $\mathrm{V}$ is the volume of the baking domain and $\mathrm{T}_{\text {zone }}$ is the set-point temperature in the flow domain. Small values of $\sigma_{T}$ indicate that the temperature is highly uniform within the baking chamber. It is generally accepted within the baking industry that good temperature uniformity within the ovens leads to better bread quality.

\subsection{Bake time model}

In the analyses carried out here, each loaf of bread is specified to have $0.25 \mathrm{~m}$ length, $0.10 \mathrm{~m}$ width and $0.12 \mathrm{~m}$ height, with constant density $\rho=330 \mathrm{~kg} / \mathrm{m}^{3}$ and temperature dependent thermal diffusivity $\alpha(\mathrm{T})$ $=\mathrm{k}(\mathrm{T}) /\left(\rho c_{\mathrm{p}}(\mathrm{T})\right)$, where $\mathrm{k}(\mathrm{T})$ and $\mathrm{c}_{\mathrm{p}}(\mathrm{T})$ are listed in Table 2 [23]. This leads to each loaf of bread having a mass of $1.0 \mathrm{~kg}$. Unlike previous analyses [18,19,24], the convective heat transfer coefficient $\mathrm{h}_{\mathrm{c}}$ here is taken as the function of $\mathrm{d}, \mathrm{H} / \mathrm{d}$ and $\mathrm{u}_{\mathrm{noz}}$ determined on an experimental pilot oven (Spooner Industries Ltd., Ilkley, UK). Bake-time predictions within the bread/dough are obtained using a simple heat transfer model within the bread/dough based on conduction only, with the bread taken as cooked when its core temperature reaches $94^{\circ} \mathrm{C}$ [15]. This approach, which is found to be consistent with industrial data, provides a straightforward coupling to the CFD analysis which can demonstrate the potential energy savings opportunity within the bread-baking industry. More complex baking models developed by other authors, incorporating moisture content and volume change, or gelatinisation [25, $26,27]$, are much more difficult to couple with CFD analysis.

The temperature inside the dough/bread is modelled by the following heat conduction equation in three dimensions, see Eq. (4):

$$
\nabla^{2} T(x, y, z)=\frac{\partial}{\partial t}\left[\frac{T}{\alpha(T)}\right]
$$


for any points $(\mathrm{x}, \mathrm{y}, \mathrm{z})$ in the domain $\mathrm{D}: 0 \leq \mathrm{x} \leq .25,0 \leq \mathrm{y} \leq 0.1,0 \leq \mathrm{z} \leq 0.12$ with the following initial conditions, $\mathrm{T}(\mathrm{x}, \mathrm{y}, \mathrm{z}, \mathrm{t}=0)=39^{\circ} \mathrm{C}$ and boundary conditions, $-\left.k \frac{\partial T}{\partial x}\right|_{\hat{x}}=h_{c}\left(d, \frac{H}{d}, U\right)\left[T(\hat{x}, t)-T_{\infty}\right]$, where $\mathrm{h}_{\mathrm{c}}$ is taken from equation (2), $T_{\infty}=513^{\circ} \mathrm{C}$ and $\hat{x}$ and are points $(\mathrm{x}, \mathrm{y}, \mathrm{z})$ on the boundary of the computational domain D. Eq. (4) is solved numerically using the finite element analysis solver COMSOL [28].

Table 2

Temperature-dependent bread properties [20]

\begin{tabular}{lll}
\hline Temperature $\left({ }^{\circ} \mathrm{C}\right)$ & Heat capacity, $\mathrm{c}_{\mathrm{p}}(\mathrm{J} / \mathrm{kg} \mathrm{K})$ & Thermal conductivity, $\mathrm{k}(\mathrm{W} / \mathrm{m} \mathrm{K})$ \\
\hline 28 & 3080.0 & 0.85 \\
60 & 2550.6 & 0.38 \\
120 & 1774.3 & 0.17 \\
227 & 1514.1 & 0.16 \\
\hline
\end{tabular}

In practice, energy-efficient baking is a compromise between achieving a faster bake time, by using a higher air velocity to increase the convective heat transfer coefficient and the larger energy consumption from the higher electricity load needed to power the fans that distribute the air. The power consumption of the fans required to distribute the air can be estimated by Eq. (5):

$$
\mathrm{P}=\Delta \mathrm{p} \cdot \mathrm{Q}
$$

In terms of the air volumetric flow rate, $\mathrm{Q}$, and pressure drop, $\Delta \mathrm{p}$. The relationship between the flow rate $\mathrm{Q}$ and the heat transfer coefficient can be inferred using Eq. (2) and the thermal energy savings from achieving a smaller bake-time can be estimated by assuming that $19 \%$ of the energy supplied to the oven is lost to ambient, as described by Paton et al. [2, 29]. The latter means that the specific energy loss ( $\mathrm{kJ}$ of energy per kg of product produced) reduces linearly with bake time. The optimum convective heat transfer coefficient which minimises the specific energy consumption ( $\mathrm{kJ}$ of energy per kg of baked bread) can be determined by balancing these two factors.

\subsection{Optimisation strategy}

A multi-objective optimisation is carried out with a fixed nozzle-to-nozzle spacing $\mathrm{S}=200 \mathrm{~mm}$ and a fixed width spacing $\mathrm{w}=40 \mathrm{~mm}$. Its goal is to minimise both the temperature variation through the functional $\sigma_{\mathrm{T}}$ and the bake time $\sigma_{\text {cooking. }}$. As noted above, the former is an indicator of product quality, while the latter has an important influence on the specific energy consumption of the baking process. Due to the computational requirements of the CFD analyses, a surrogate modelling approach is adopted for the optimisation study, a methodology that has been used successfully by the authors for a range of engineering applications, e.g. the design optimisation of jet pumps [30], superhydrophobic functional surfaces [31] and emergency response vehicles [32]. The three-dimensional design space is explored efficiently using a nested optimal Latin Hypercube Design of Experiments (DOE) approach which exploits a permutation genetic algorithm to achieve a uniform spread of points within the design space. The optimality criterion for the three DOEs is characterised by Eq. (6) where each objective function is defined by Eq. (7):

$$
\begin{aligned}
\mathrm{F} & =\mathrm{W}_{\mathrm{b}} \mathrm{U}_{\mathrm{b}}+\mathrm{W}_{\mathrm{v}} \mathrm{U}_{\mathrm{v}}+\mathrm{W}_{\mathrm{m}} \mathrm{U}_{\mathrm{m}} \\
\mathrm{U} & =\sum_{\mathrm{i}=1}^{\mathrm{P}} \sum_{\mathrm{j}=\mathrm{i}+1}^{\mathrm{P}} \frac{1}{\mathrm{~L}_{\mathrm{ij}}}
\end{aligned}
$$

where $U$ is a pseudo-potential energy of DOE points, $L_{i j}$ is the distance between points $i$ and $j$ where $i$ $\neq \mathrm{j}, \mathrm{F}$ is the objective function to be minimized, $\mathrm{W}$ is weighting factors, and, $\mathrm{b}, \mathrm{v}, \mathrm{m}$ denote model building, model validation and merged DOEs respectively [33]. 
The Moving Least-Squares (MLS) method is used to build the surrogate models of $\sigma_{T}$ and bake time, where a Gaussian weight decay function is used to determine the weighting of points in the regression analysis at each point:

$$
\mathrm{w}_{\mathrm{i}}=\exp \left(-\theta \mathrm{r}_{\mathrm{i}}^{2}\right)
$$

An Optimal Latin Hypercube DOE is constructed in the unit cube with 30 points in the three dimensions, 20 of which are building points and 10 validation points, and equal weights applied in Eq. (6). The levels of the Latin Hypercube are then scaled to correspond to their respective design variable ranges of $5 \mathrm{~mm} \leq \mathrm{x}_{1} \leq 20 \mathrm{~mm} ; 2 \leq \mathrm{x}_{2} \leq 10$; and $8 \mathrm{~m} / \mathrm{s} \leq \mathrm{x}_{3} \leq 40 \mathrm{~m} / \mathrm{s}$, which are specified to account for the operating and geometric conditions of the oven. The uniform distribution of the final set of DOE points is shown in Fig. 6.

Figure 6: Charts of the minimum distances between the DOE points for: (a) Model building DOE, (b) Model validation DOE and (c) Merged DOE.

The surrogate models for the temperature uniformity functional $\sigma_{\mathrm{T}}$ and the cooking time, $\sigma_{\text {cooking }}$ are built by carrying out CFD calculations and COMSOL solutions of Eq. (4) respectively at each of the DOE points and using these values to build MLS surrogate models of their dependence on the design variables throughout the design space. The MLS models use a second order base polynomial and the closeness of fit parameter (the parameter $\theta$ in Eq. (8)) is optimized by minimising the Root Mean Square Error between the predictions of the surrogate models and the actual CFD/COMSOL predictions at the 10 model validation points. The optimised MLS models gave very good agreement with building, validations and combined DOEs: $\mathrm{R}^{2}$ values of $0.9999,0.9927$ and 0.9999 for $\mathrm{DOE}_{\mathrm{b}}$, $\mathrm{DOE}_{\mathrm{v}}$ and $\mathrm{DOE}_{\mathrm{m}}$ respectively for $\sigma_{\mathrm{T}}$ and $\mathrm{R}^{2}$ values of $0.9996,0.9908$ and 0.9993 for $\mathrm{DOE}_{\mathrm{b}}, \mathrm{DOE}_{\mathrm{v}}$ and $\mathrm{DOE}_{\mathrm{m}}$ respectively for $\sigma_{\text {cooking. }}$.

\section{$3 \quad$ Results and discussion}

The CFD predictions show that the flow field within the baking chamber is dominated by large regions of recirculating flow which lead to variations in temperature uniformity throughout the chamber, the highest temperatures being associated with the interior of the recirculating flow regions, $[2,10,12,18]$

\subsection{Multi-objective CFD optimisation}

The design goal is formulated as the unconstrained, multi-objective optimization problem of minimizing the objective functions $\sigma_{\mathrm{T}}$ and $\sigma_{\text {cooking }}$ simultaneously. The global minima of the surrogate models for $\sigma_{\mathrm{T}}$ and $\sigma_{\text {cooking }}$ were obtained using a multi-objective genetic algorithm (GA) approach. The GA identified optimal designs which, as predicted by the surrogate models, would reduce the temperature difference between the top of the bread (i.e. the bottom wall plate in our 3D CFD generic model) and the baking chamber temperature, as well as decreasing the time to cook the bread. The parameters of the optimal design were obtained as follows: $d=18.3 \mathrm{~mm}, \mathrm{H} / \mathrm{d}=8$ and $\mathrm{u}_{\mathrm{noz}}=30.4 \mathrm{~m} / \mathrm{s}$ with consequential objective function $\sigma_{\mathrm{T}}=10.9 \mathrm{~K}$ and $\sigma_{\text {cooking }}=21.9 \mathrm{~min}$ from the surrogate models. Functions showing the dependence of $\sigma_{\mathrm{T}}$ and the bake time $\sigma_{\text {cooking }}$ on the design variables were generated from the $30 \mathrm{DOE}$ points. Illustrative examples of functions $\sigma_{\mathrm{T}}$ and bake time $\sigma_{\text {cooking }}$ in terms of the design variables $\mathrm{H} / \mathrm{d}$ and $\mathrm{u}_{\text {noz }}$ are shown in Figures 7 and 8 respectively.

Figure 7: Function of $\sigma_{\mathrm{T}}$ from the surrogate model. 
Figure 8: Function of $\sigma_{\text {cooking }}$ from the surrogate model.

The optimized designs from the surrogate models were validated against corresponding CFD solutions with the same design variables. They showed good agreement with the surrogate models with a $\sigma_{\mathrm{T}}=10.88$ and $\sigma_{\text {cooking }}=21.99$ which are within $0.2 \%$ of the surrogates' predictions. The results of the validation process and the predicted oven performance objective functions $\sigma_{\mathrm{T}}$ and $\sigma_{\text {cooking }}$ are given in Table 3.

Table 3

Oven performance at stages of the design process

\begin{tabular}{llll}
\hline & Response from & $\sigma_{\mathrm{T}}(\mathrm{K})$ & $\sigma_{\text {cooking }}(\min )$ \\
\hline Best design from DOE & CFD & 11.24 & 21.45 \\
$\begin{array}{l}\text { Optimized design after GA } \\
\begin{array}{l}\text { CFD prediction with } \\
\text { optimized design variables }\end{array}\end{array}$ & MLS & 10.9 & 21.98 \\
\hline
\end{tabular}

The use of the multi-objective CFD optimisation for optimising specific energy consumption is considered next.

\subsection{Optimisation of Specific Energy Consumption}

Figure 7 shows that for a given $\mathrm{u}_{\text {noz }}$, the temperature uniformity generally increases with increasing $\mathrm{H} / \mathrm{d}$ but that the dependence on $\mathrm{u}_{\text {noz }}$ is more complex due to the interaction between the air speed and the resulting geometry of the air jet. The dependence of the heat transfer coefficient on the design variables is known from the experimental correlation, Eq. 2, and Figure 8 shows that increasing $\mathrm{u}_{\text {noz }}$ increases the convective heat transfer coefficient into the bread. The resultant increase in energy transfer into the bread reduces the cooking time, albeit with greater energy losses to ambient. The optimal configuration in terms of specific energy consumption ( $\mathrm{kJ}$ of energy per $\mathrm{kg}$ of product) represents the best compromise between energy supply to the bread and energy losses to ambient.

Following the system modelling approach and analysis developed by the authors (explained in detail in [2]) and assuming a commercial oven with a typical energy consumption of $800 \mathrm{~kJ} / \mathrm{kg}$ and heat losses of $380 \mathrm{~kW}$, the energy required to cook the bread can be inferred from the cooking time predicted by the optimisation. This is calculated by using the assumption that heat losses to atmosphere (i.e. losses through oven walls and in flue gases) remain constant with increased throughput - thus reducing the cooking time and increasing the product throughput reduces the amount of heat loss per $\mathrm{kg}$ of bread baked.

In a multi-objective optimisation problem a Pareto front can be used by designers to choose the most appropriate compromise between the various objective functions that have been identified and for which the goal is to minimise the objective functions. It is not possible to move along the design points on the Pareto front to decrease any of the objective functions without increasing at least one other objective function, and Pareto points are often referred to as being 'non-dominated'. In the present case with two objective functions the Pareto front showing the impact of the two objectives of interest here is shown in Figures 9 and 10. This data provides a convenient and scientifically-rigorous means by which oven designers can quantify the effect of their design criteria on both product quality and energy efficiency of forced convection bread baking ovens.

Figure 9: Pareto front showing the compromises that can be struck in minimising both $\sigma_{\mathrm{T}}$ and $\sigma_{\text {cooking }}$ during commercial bread baking together with three representative design points (e.g. P1, P2 and P3) used for the oven performance analysis illustrated in Table 4.

Figure 10: Pareto front illustrating the compromises that can be made for reducing both $\sigma_{\mathrm{T}}$ and specific energy during commercial bread baking together with the same three corresponding design points depicted in Figure 9 used for the oven performance analysis illustrated in Table 4. 
As an illustration, the oven performance of three representative operating conditions designs on the Pareto front as indicated in Figures 9 and 10 is presented in Table 4. The corresponding design variables, namely $\mathrm{d}, \mathrm{H} / \mathrm{d}$ and $\mathrm{u}_{\text {noz }}$ with the two objectives $\sigma_{\mathrm{T}}, \sigma_{\text {cooking }}$ and specific energy are also specified. The $\mathrm{H} / \mathrm{d}$ ratio for the optimum design is within the range of 6-8 that has been proposed by previous studies $[34,35]$ unlike the ones found for designs P1 and P3. The corresponding ratio s/d of around 10 for the optimum design is in accurate agreement with the analysis carried out by Attalla and Specht [36] whereas this is not the case for design P2 (e.g. s/d $\approx 18.5$ ).

The optimum design obtained would allow the bread to cook the bread in $\sigma_{\text {cooking }} \approx 22$ min with $\sigma_{\mathrm{T}} \approx$ $10{ }^{\circ} \mathrm{C}$ with a total specific energy of about $806 \mathrm{~kJ} / \mathrm{kg}$. This would lead to $7-10 \%$ reduction in baking time that results in increased plant efficiency for values of $\sigma_{\text {cooking }}$ and $\sigma_{\mathrm{T}}$ in the region of $23.5-24.0$ min and $15-35^{\circ} \mathrm{C}$ respectively.

Table 4

Oven design performance at three operating conditions points located on the Pareto front as shown in Figures 10 and 11.

\begin{tabular}{lrcllll}
\hline $\begin{array}{l}\text { Design point } \\
\text { Pareto front }\end{array}$ & $\mathrm{d}(\mathrm{mm})$ & $\mathrm{H} / \mathrm{d}$ & $\mathrm{u}_{\text {noz }}(\mathrm{m} / \mathrm{s})$ & $\sigma_{\mathrm{T}}(\mathrm{K})$ & $\sigma_{\text {cooking }}(\min )$ & $\begin{array}{l}\text { Specific energy } \\
(\mathrm{kJ} / \mathrm{kg})\end{array}$ \\
\hline $\mathrm{P} 1$ & 9.14 & 5.86 & 40.00 & 35.76 & 21.51 & 745.64 \\
$\mathrm{P} 2$ & 10.98 & 6.41 & 28.97 & 12.89 & 21.97 & 756.23 \\
$\mathrm{P} 3$ & 19.48 & 5.59 & 22.85 & 10.87 & 22.85 & 795.75 \\
\hline $\begin{array}{l}\text { Optimum } \\
\text { design }\end{array}$ & 18.30 & 8.00 & 30.40 & 10.90 & 21.90 & 806.00 \\
\hline
\end{tabular}

Table 5 summarises the overall scaled-up energy benefit to the baking industry. Based on worldwide annual bread consumption of about 9.5 billion kg per year [1] the total value for potential worldwide savings is $446.3-637.6 \mathrm{GWh}$. This clearly indicates a strong case both economically and environmentally to design and manufacture energy optimised commercial baking ovens.

Table 5

Worldwide potential energy savings

\begin{tabular}{llll}
\hline Region & $\begin{array}{l}\text { Annual production } \\
\text { (,000's tonnes) [1] }\end{array}$ & $\begin{array}{l}\text { Percentage of production } \\
\text { classified as 'industrial' } \\
{[30]}\end{array}$ & GWh saving \\
\hline Asia-Pacific & 8514.4 & $57 \%$ & $75.5-107.9$ \\
Europe & 50235.0 & $41 \%$ & $320.4-457.7$ \\
Americas & 28286.8 & Unknown & $>>50.4-72.0$ \\
Worldwide & $\mathbf{9 4 6 0 4 . 6}$ & $\mathbf{3 8 . 2 \%}$ & $>\mathbf{4 4 6 . 3 - 6 3 7 . 6}$ \\
\hline
\end{tabular}

\section{Conclusions}

High fidelity CFD analysis of the thermal airflows in the baking chamber of commercial bread ovens, coupled to a heat diffusion-based bread baking model via experimentally-determined heat transfer coefficients, provides a scientifically-rigorous means of optimising baking operations subject to multiobjective design criteria. Important practical criteria include the achievement of temperature uniformity within the oven, which leads to good product quality and more energy-efficient baking with low specific energy consumption. In the present study these criteria have been applied to identify an optimised oven design with nozzle jets diameter $\mathrm{d}=18.3 \mathrm{~mm}$, dimensionless nozzle-to-surface 
distance $\mathrm{H} / \mathrm{d}=8$ and nozzle jets velocity $\mathrm{u}_{\mathrm{noz}}=30.4 \mathrm{~m} / \mathrm{s}$, resulting in a temperature uniformity $\sigma_{\mathrm{T}}=$ $10.9 \mathrm{~K}$ and cooking time $\sigma_{\text {cooking }}=21.98 \mathrm{~min}$ and a total specific energy of about $806 \mathrm{~kJ} / \mathrm{kg}$. Previous related studies have shown that such an approach can enable designers to reduce energy usage by at least $5 \%$ on top of the $10 \%$ saving that can be gained through optimisation for temperature uniformity [37].

Energy savings can be further increased for smaller, denser or less porous baked products where thermal conductivity to the core of the bread is less of a barrier. The scientific data and insights from such formal scientific analyses are beginning to be adopted within the UK's bread baking industry. The optimisation methodology presented here is being applied to a much wider range of oven designs and operating conditions. Lastly, it should be noted that the CFD-based optimisation methodology developed in the paper could be of benefit to others industries such as paper or food processing (e.g. pasta, baked products) as well as cooling and data centres for instance.

\section{Acknowledgement}

The financial support of the UK's Engineering and Physical Sciences Research Council through Grant EP/G058504/1 is gratefully acknowledged. The authors also thank Spooner Industries Ltd for providing access to their pilot plant baking oven and to Warburtons Ltd for their support of this work.

\section{References}

[1] Bread \& Rolls Industry Profile: Global, in Bread \& Rolls Industry Profile: United Kingdom (2011), Datamonitor Plc. p. 37.

[2] Paton JB, Khatir Z, Thompson HM, Kapur N, Toropov VV. Thermal energy management in the bread-baking industry using a system modelling approach. Appl Therm Eng, 53(2): 340-347, 2013.

[3] Therdthai N, Zhou WB, Adamczak T. Optimisation of the temperature profile in bread baking. J Food Eng 2002; 55:41-8.

[4] Carbon Trust independent experts on carbon reduction \& sustainability http://www.carbontrust.com/

[5] Industrial Energy Efficiency Accelerator - Guide to the industrial bakery sector, Carbon Trust Report CGT034, 2010.

[6] European Commission Energy - Energy Efficiency Directive,http://ec.europa.eu/energy/efficiency [7] Pask F., Sadhukhan J., Lake P., McKenna S., Perez E., Yang A. Systematic approach to industrial oven optimisation for energy saving. Appl Therm Eng, 71: 72-77, 2014.

[8] Pask F., Sadhukhan J., Lake P., McKenna S., Perez E., Yang A., 2014, Practical approach for engineers to optimise industrial ovens for energy saving, Chemical Engineering Transactions, 39, 865-870 DOI:10.3303/CET1439145.

[9] Martin H. Heat and Mass Transfer between Impinging Gas Jets and Solid Surfaces. Adv in Heat Transfer 1977; 13:1-60.

[10] Norton T, Sun D-W. Computational fluid dynamics (CFD) - an effective and efficient design and analysis tool for the food industry: A review. Trends in Food Sci \& Technol 2006; 17:600-20.

[11] Khatir Z, Paton JB, Thompson HM, Kapur N, Toropov VV, Lawes M, Kirk D. Computational fluid dynamics (CFD) investigation of air flow and temperature distribution in a small scale breadbaking oven. Appl Energy, 2012; 89:89-96.

[12] Khatir Z, Thompson HM, Kapur N, Toropov VV, Paton JB. The application of Computational Fluid Dynamics and design optimisation in the British bread-baking industry. In Proceedings of the 8th international conference on CFD in the oil \& gas, metallurgical and process industries, Trondheim Norway, 21-23 June 2011.

[13] Therdthai N, Zhou WB, Adamczak T. Two-dimensional CFD modelling and simulation of an industrial continuous bread baking oven. J Food Eng 2003; 60:211-7. 
[14] Therdthai N, Zhou WB, Adamczak T. Three-dimensional CFD modelling and simulation of the temperature profiles and airflow patterns during a continuous industrial baking process. J Food Eng 2004; 65:599-608.

[15] Purlis E. Bread baking: Technological considerations based on process modelling and simulation. J Food Eng 2011; 103:92-102.

[16] Hadiyanto, Boom RM, Van Straten G, Van Boxtel AJB, Esveld DC. Multi-objective optimization to improve the product range of baking systems. J Food Process Eng 2009; 32:709-29. [17] Patakar SV, Spalding DB. Calculation procedure for heat, mass and momentum-transfer in 3dimensional parabolic flows. Intern J of Heat and Mass Transfer 1972; 15(10): 1787-1806.

[18] Khatir Z, Paton JB, Thompson HM, Kapur N and Toropov VV. Optimisation of the energy efficiency of bread-baking ovens using a combined experimental and computational approach. Applied Energy 2013, 112: 918-927.

[19] Khatir Z, Thompson HM, Kapur N, Toropov VV, Paton JB. Multi-objective computational fluid dynamics (CFD) design optimisation in commercial bread-baking. In the twelfth UK National Heat Transfer Conference (UKHTC 2011) 2011, Leeds, UK.

[20] Boulet M, Marcos B, Dostie M, Moresoli C. CFD modeling of heat transfer and flow field in a bakery pilot oven. J Food Eng 2010, 97(3):393-402.

[21] Ansys Inc, 2013, http://www.ansys.com-

/Products/Simulation+Technology/Fluid+Dynamics/Fluid+Dynamics+Products/ANSYS+Fluent.

[22] S.J. Wang, A.S. Mujumdar, A comparative study of five low Reynolds number k-epsilon models for impingement heat transfer, Appl Therm Eng 25 (2005) 31-44.

[23] Wong SY, Zhou WB, Hua, JS. CFD modeling of an industrial continuous bread-baking process involving U-movement. J Food Eng 2007; 78(3):888-896.

[24] Khatir Z, Paton JB, Thompson HM, Kapur N and Toropov VV. A multi-objective design methodology to improve energy efficiency in the bread-baking industry. Proceedings of 2012 European Federation of Food Science \& Technology (EFFoST) Annual Meeting, 20-23 November 2012, Montpellier, France.

[25] J. Zhang and A.K. Datta, Mathematical modeling of bread baking process, Journal of Food Engineering, 75(1), (2006) 78-89.

[26] D.R. Jefferson, A.A. Lacey. and P.A. Sadd, Crust density in bread baking: Mathematical modelling and numerical solutions, Applied Mathematical Modelling, 31(2), (2007) 209-225.

[27] P.C. Bollada, Expansion of elastic bodies with application in the bread industry, Mathematical and Computer Modelling, 48(7-8), (2008) 1055-1067.

[28] COMSOL Multiphysics ${ }^{\circledR}$ Engineering Simulation Software (http://www.comsol.com).

[29] Paton JB, Khatir Z, Thompson HM, Kapur N, Toropov VV. Integration of System-Modelling and Computational Methods for Energy Reductions in the Bread Industry. In: Sustainable Thermal Energy Management International Conference (SusTEM 2011) 2011, Newcastle upon Tyne, UK. 49-57.

[30] J. Fan, J. Eves, H.M. Thompson, V.V. Toropov, N. Kapur, D. Copley, A. Mincher, Computational fluid dynamic analysis and design optimization of jet pumps, Computers \& Fluids 46 (1) (2011) 212e217. http://dx.doi.org/10.1016/j.compfluid.2010.10.024.

[31] Z. Khatir and K.J. Kubiak, CFD based optimisation of the superhydrophobic functional surface in dropwise condensation, Proceedings of International Conference on the Analysis and Mathematical Applications in Engineering and Science (AMAES 2014), 19 - 22 January 2014, Curtin University Sarawak, Miri, Malaysia.

[32] A.R. Taherkhani, P.H. Gaskell, R.W. Hewson, Z. Khatir, A. Polynkin, H.M. Thompson and V.V. Toropov, Aerodynamic Design Optimization of Emergency Response Vehicles Using Computational Fluid Dynamics, Proceedings of 9th ASMO UK/ISSMO Conference on Engineering Design Optimization Product and Process Improvement, University College Cork, Cork, Ireland, July $5^{\text {th }}-6^{\text {th }}$, 2012.

[33] Narayanan, A., Toropov, V.V., Wood, A.S. and Campean I.F. Simultaneous model building and validation with uniform designs of experiments. Engineering Optimization, 39(5): 497-512, 2007.

[34] Gardon, R. and Akfirat, J.C. Heat Transfer characteristics of impinging two-dimensional air jets. Journal of Heat Transfer 1966, 88 (1), 101-107.

[35] Sarkar, A. and Singh, R.P. Air impingement technology for food processing: visualization studies. LWT - Food Science and Technology 2004, 37 (8), 873-879. 
[36] Attala, M. and Specht, E. Heat transfer characteristics from in-line arrays of free impinging jets. Heat and Mass Transfer 2009, 45 (5), 537-543.

[37] Khatir Z, Thompson H.M., Kapur N, Toropov V.V. and Paton J.B. Multi-objective computational fluid dynamics (CFD) design optimisation in commercial bread-baking. Appl Therm Eng 2013, 60: 480-486, 2013. 


\section{Captions of Figures}

Figure 1: Schematic diagram of a forced convection commercial bread oven: (a) Overall view and (b) Cross section view.

Figure 3: Representative geometry of a nozzle configuration showing design variables: nozzle jet diameter, $\mathrm{d}$, jet velocity, $\mathrm{u}_{\mathrm{noz}}$ and distance $\mathrm{H}$ between the nozzle jet and the bottom wall, with nozzle to nozzle distance spacing, $\mathrm{s}=0.2 \mathrm{~m}$ and $\mathrm{w}=0.04 \mathrm{~m}$.

Figure 2: Process diagram emphasising the link between energy savings and high fidelity design optimisation.

Figure 4: Top view of the perforated plate and the solution zone (dotted line) used for computational simulations.

Figure 5: Generic model of the oven baking chamber showing the boundary conditions.

Figure 6: Charts of the minimum distances between the DOE points for: (a) Model building DOE, (b) Model validation DOE and (c) Merged DOE.

Figure 7: Function of $\sigma_{\mathrm{T}}$ from the surrogate model.

Figure 8: Function of $\sigma_{\text {cooking }}$ from the surrogate model.

Figure 9: Pareto front showing the compromises that can be struck in minimising both $\sigma_{\mathrm{T}}$ and $\sigma_{\text {cooking }}$ during commercial bread baking together with three representative design points (e.g. P1, P2 and P3) used for the oven performance analysis illustrated in Table 4.

Figure 10: Pareto front emphasising the compromises that can be made for reducing both $\sigma_{\mathrm{T}}$ and specific energy during commercial bread baking together with the same three corresponding design points depicted in Figure 9 used for the oven performance analysis illustrated in Table 4.

\section{Total Figures: 10}


(a)

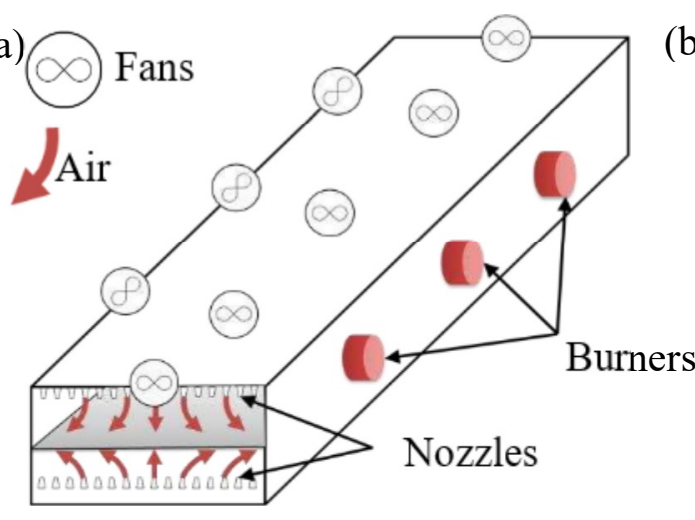

(b)

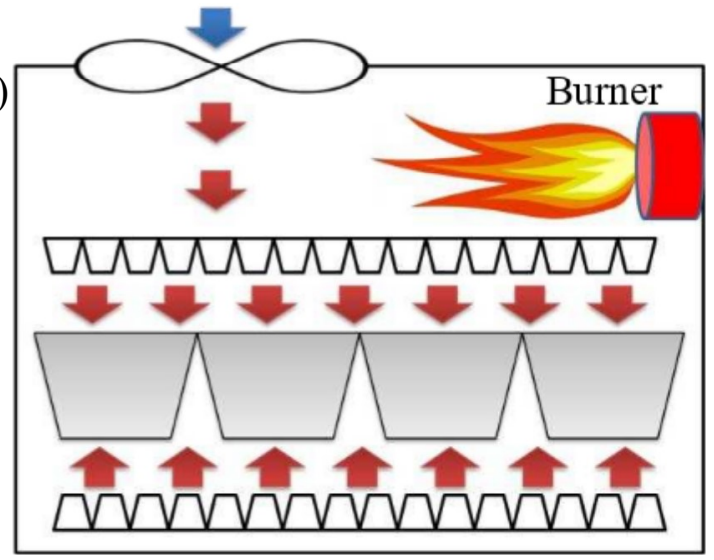

Figure 1: Schematic diagram of a forced convection commercial bread oven:

(a) Overall view and (b) Cross section view.

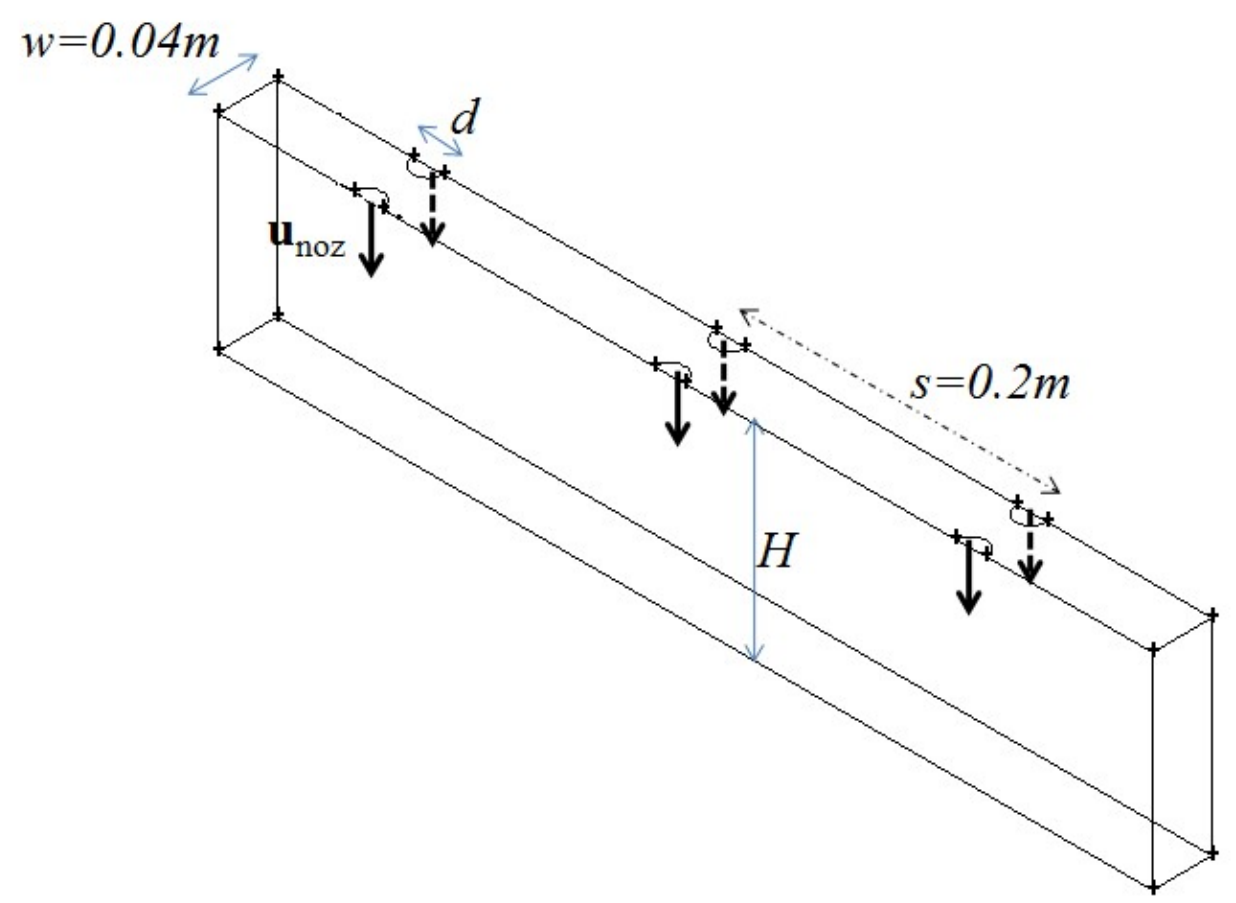

Figure 2: Representative geometry of a nozzle configuration showing design variables: nozzle jet diameter, $d$, jet velocity, $\mathrm{u}_{\text {noz }}$ and distance $\mathrm{H}$ between the nozzle jet and the bottom wall, with nozzle to nozzle distance spacing, $\mathrm{s}=0.2 \mathrm{~m}$ and $\mathrm{w}=0.04 \mathrm{~m}$. 


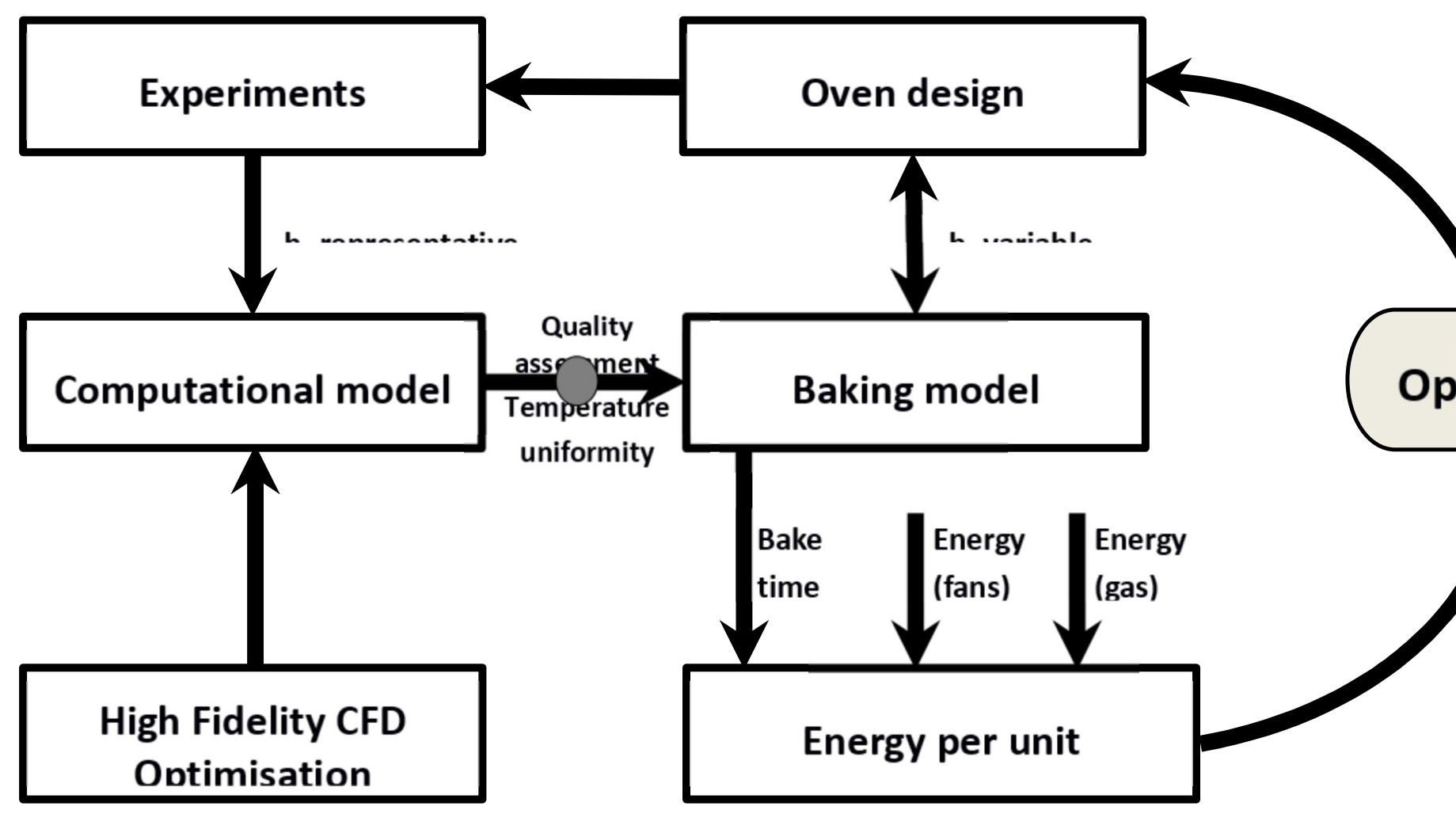

Figure 3: Process diagram emphasising the link between energy savings and high fidelity design optimisation.

\begin{tabular}{|c|c|c|c|c|c|c|c|}
\hline 0 & 0 & 0 & 0 & 0 & $\phi d$ & 0 & 0 \\
\hline 0 & 0 & 0 & 0 & 0 & 0 & 0 & 0 \\
\hline 0 & 0 & 0 & 0 & 0 & 0 & 0 & 0 \\
\hline 0 & 0 & 0 & 0 & 0 & 0 & 0 & 0 \\
\hline 0 & 0 & 0 & 0 & 0 & 0 & 0 & 0 \\
\hline 0 & 0 & "ö" & $0.6 \mathrm{mon}$ & "ö"'s" & 0 & 0 & 0 \\
\hline 0 & 0 & 0 & 0 & 0 & nO & 0 & 0 \\
\hline 0 & 0 & 0 & 0 & i & $0^{w}=0.04$ & 0 & 0 \\
\hline 0 & 0 & 0 & o & $0^{-}$ & 0 & 0 & 0 \\
\hline 0 & 0 & $\lessdot$ & $=0.2 \mathrm{~m}$ & 0 & 0 & 0 & 0 \\
\hline 0 & 0 & 0 & 0 & 0 & 0 & 0 & 0 \\
\hline 0 & 0 & 0 & 0 & 0 & 0 & 0 & 0 \\
\hline 0 & 0 & 0 & 0 & 0 & 0 & 0 & 0 \\
\hline 0 & 0 & 0 & 0 & 0 & 0 & 0 & 0 \\
\hline 0 & 0 & 0 & 0 & 0 & 0 & 0 & 0 \\
\hline 0 & 0 & 0 & 0 & 0 & 0 & 0 & 0 \\
\hline 0 & 0 & 0 & 0 & 0 & 0 & 0 & 0 \\
\hline 0 & 0 & 0 & 0 & 0 & 0 & 0 & 0 \\
\hline
\end{tabular}

Figure 4: Top view of the perforated plate and the solution zone (dotted line) used for computational simulations. 


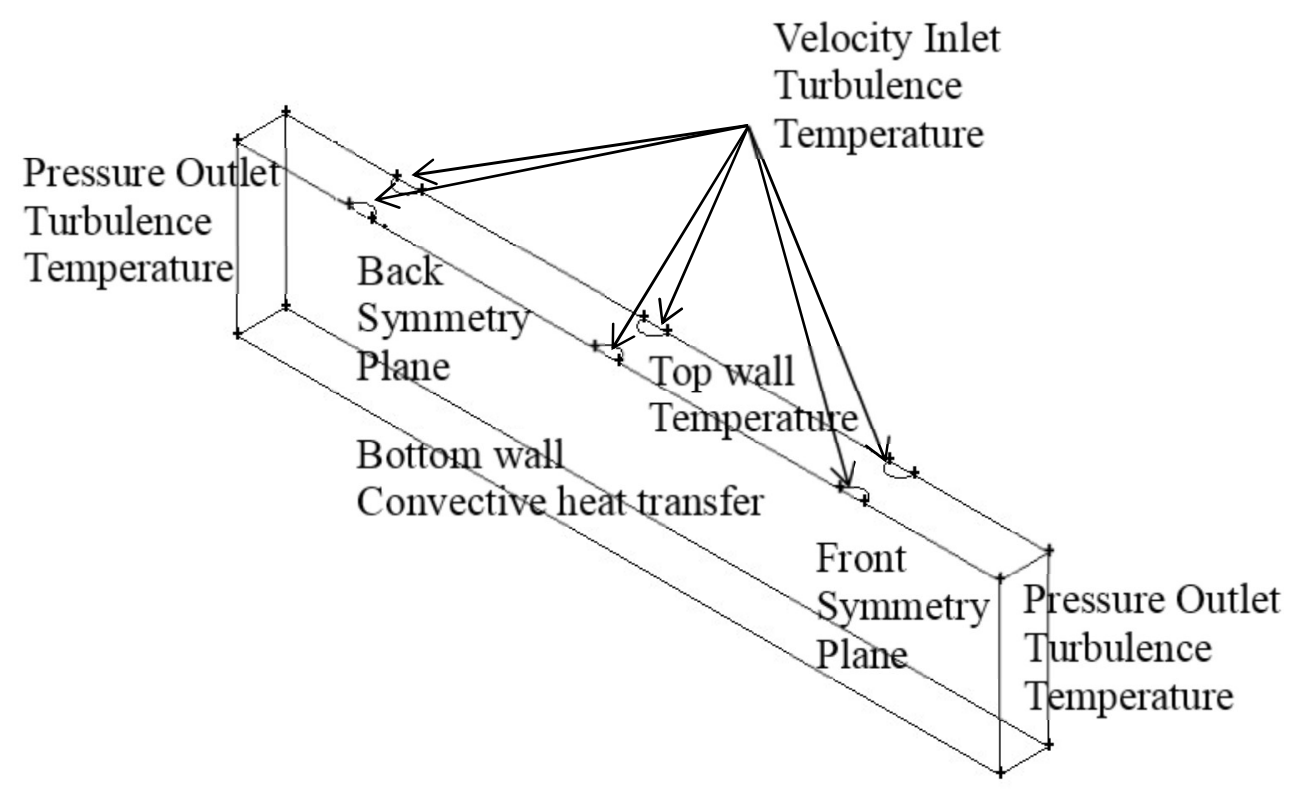

Figure 5: Generic model of the oven baking chamber showing the boundary conditions.
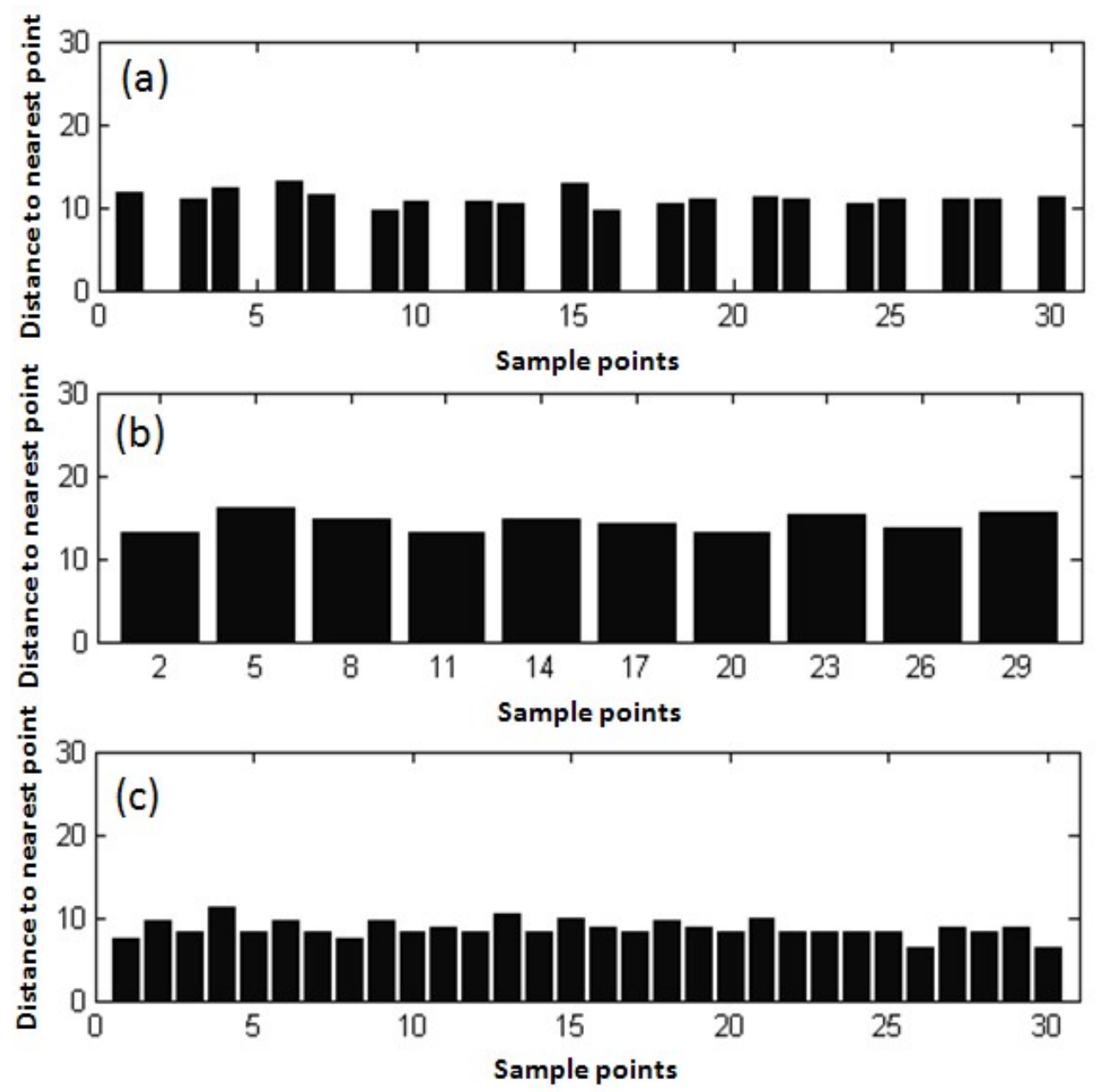
Figure 6: Charts of the minimum distances between the DOE points for:

(a) Model building DOE, (b) Model validation DOE and (c) Merged DOE.

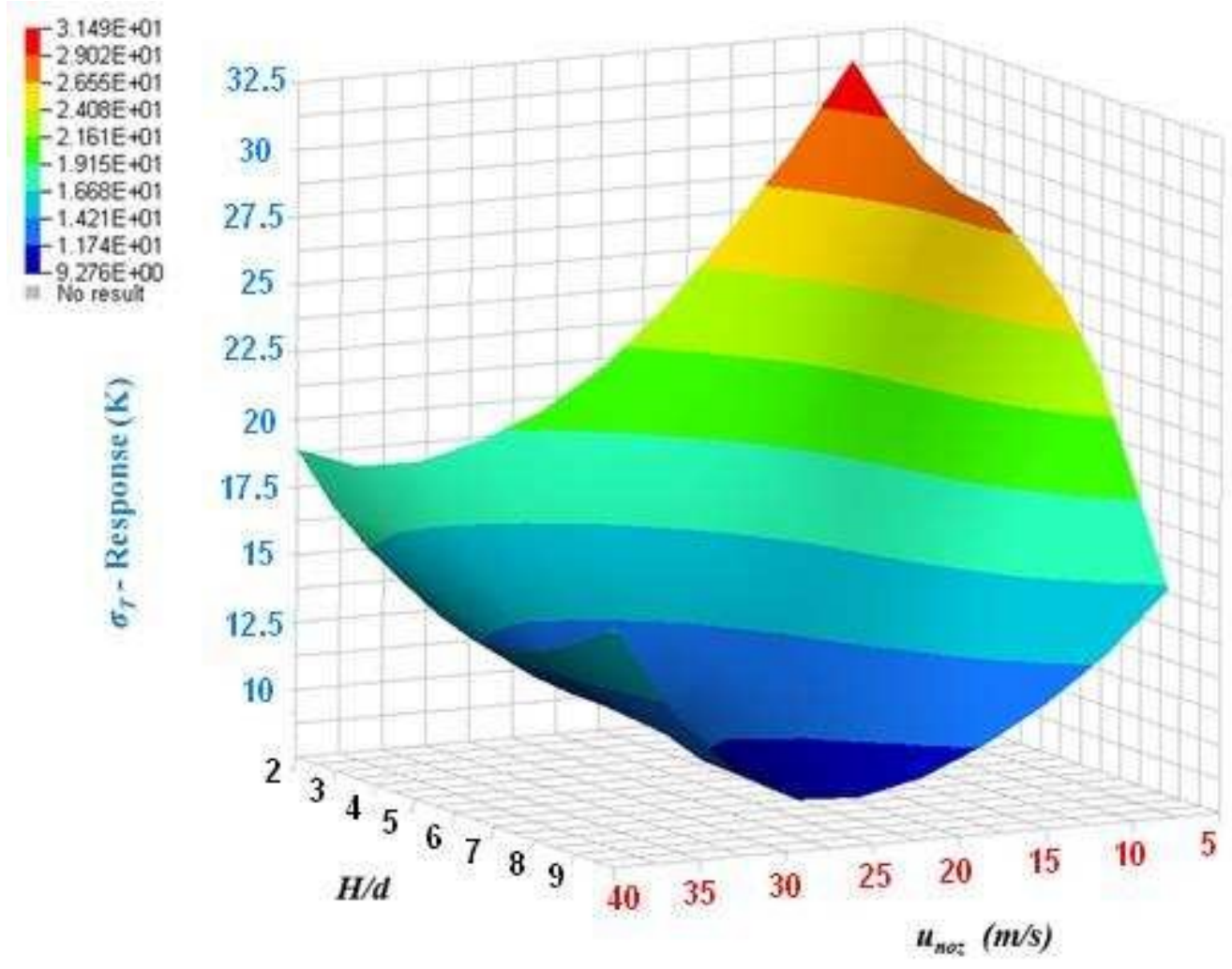

Figure 7: Function $\sigma_{\mathrm{T}}$ from the surrogate model. 


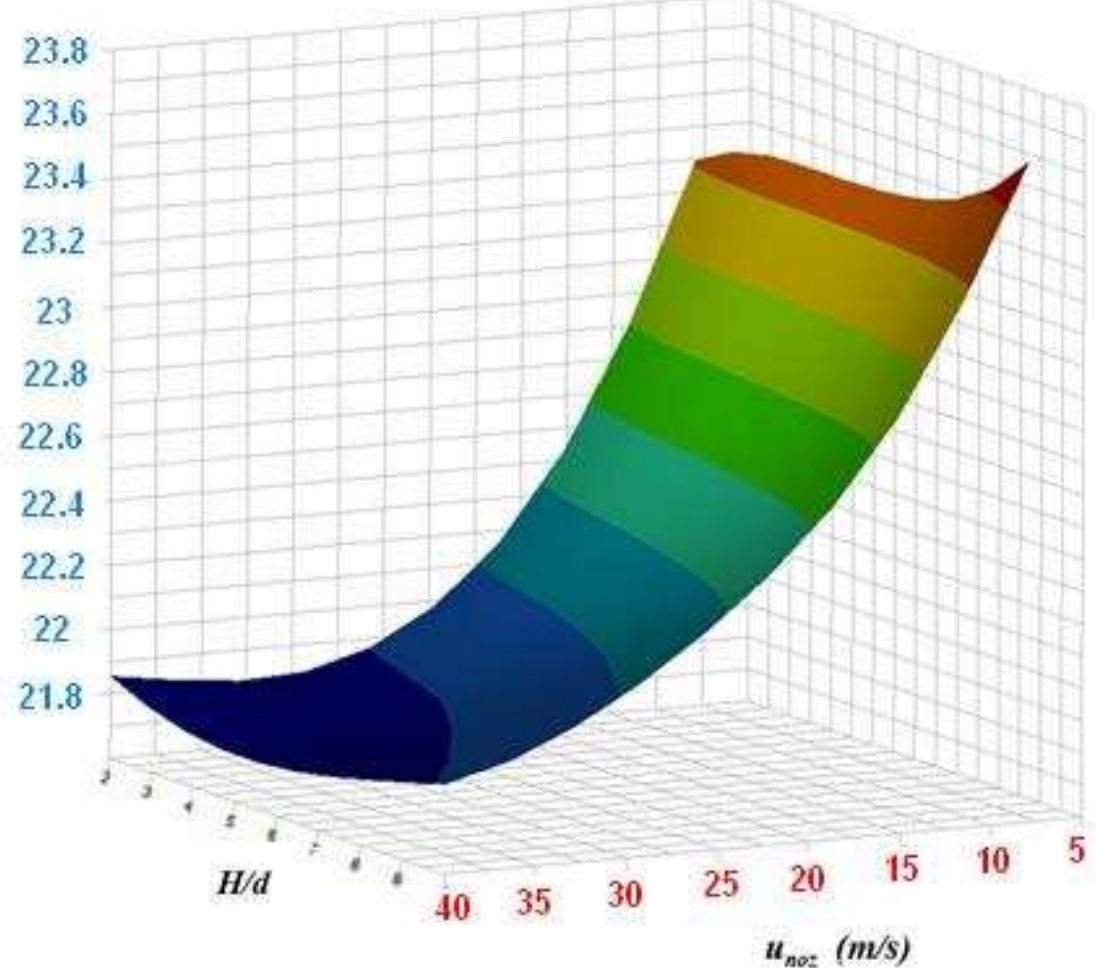

Figure 8: Function of $\sigma_{\text {cooking }}$ from the surrogate model.

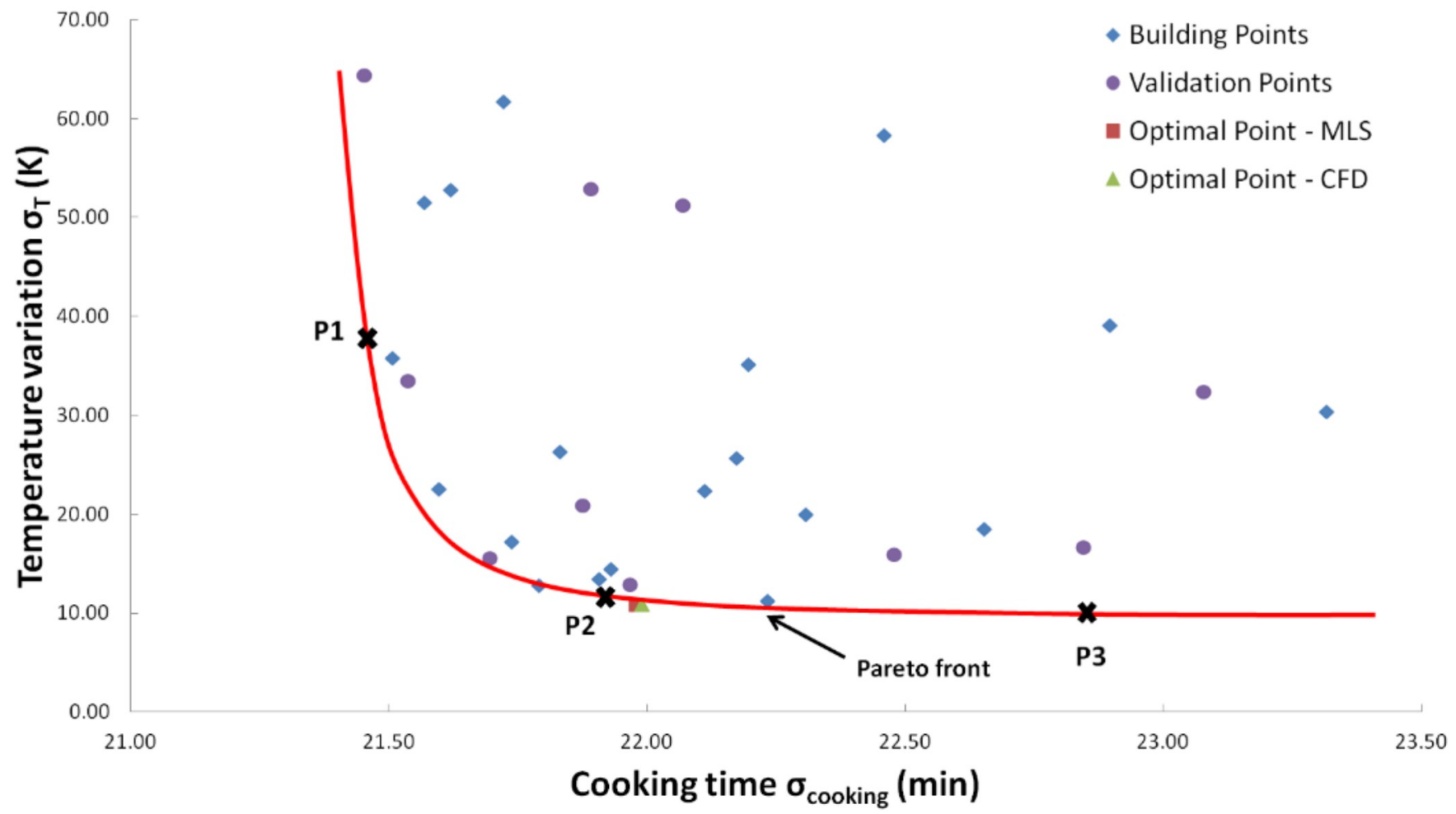

Figure 9: Pareto front showing the compromises that can be struck in minimising both $\sigma_{\mathrm{T}}$ and $\sigma_{\text {cooking }}$ during commercial bread baking together with three representative design points (e.g. P1, P2 and P3) used for the oven performance analysis illustrated in Table 4. 


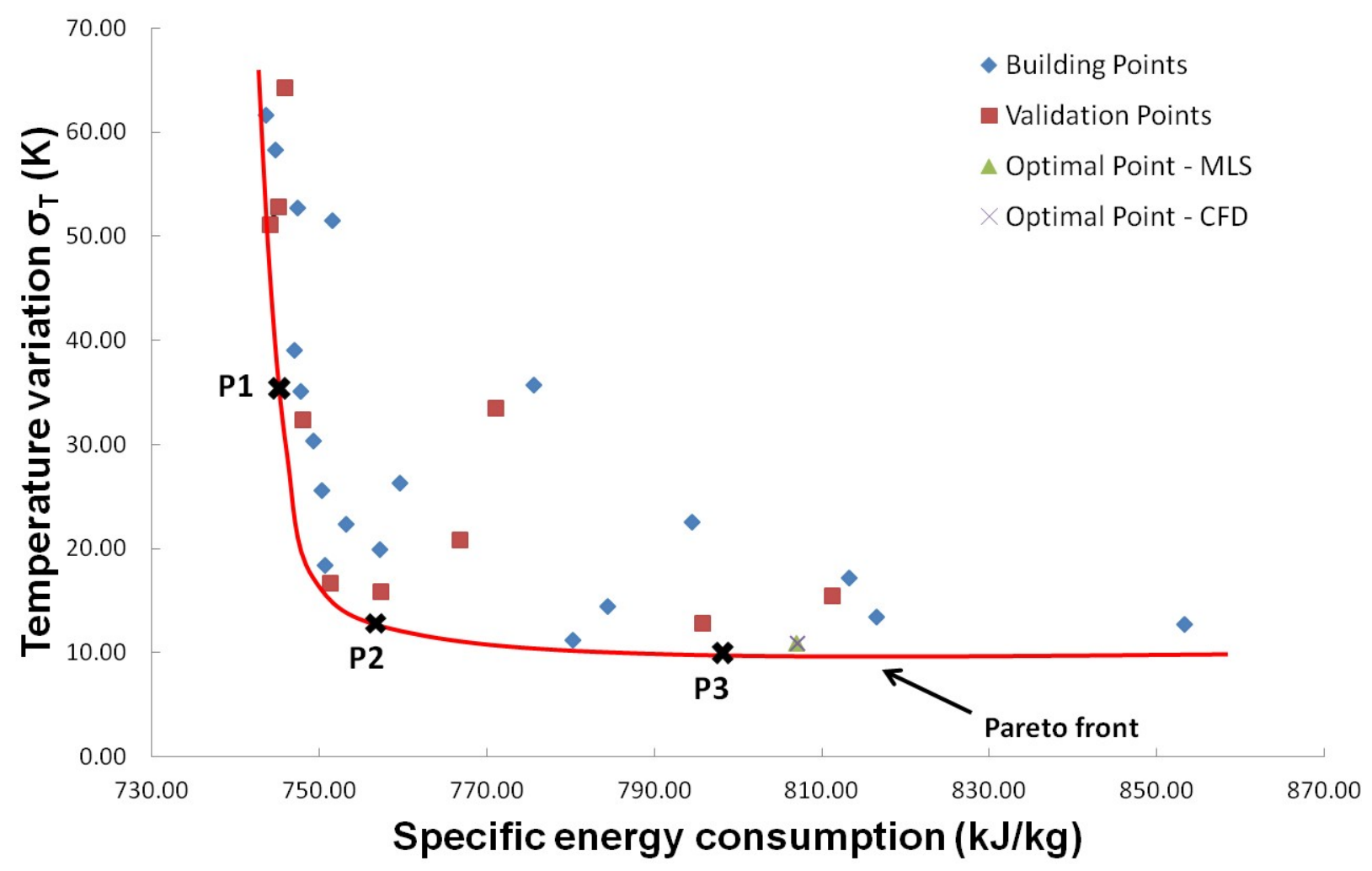

Figure 10: Pareto front emphasising the compromises that can be made for reducing both $\sigma_{\mathrm{T}}$ and specific energy during commercial bread baking together with the same three corresponding design points depicted in Figure 9 used for the oven performance analysis illustrated in Table 4. 